\title{
Die Ampsposisie van die Vrou
}

\author{
H G VAN DER WESTHUIZEN
}

Waardering vir prof van $\mathrm{Zyl}$

As een van prof dr F J van Zyl se eerste teologiese studente, en as sy eerste gepromoveerde student, is dit ' $n$ dankbare voorreg vir my om 'n bydrae in hierdie Van Zyl dedicata publikasie te lewer.

By al die mooi en goeie eienskappe en akademiese bekwaamhede, het hy uitstaande diens gelewer aan ons Kerk in onder andere die sending en die Nederduitsch Hervormde Sustersvereniging. Waar sy diens op hierdie twee terreine uit die aard van die omstandighede veral indirek was, en dus nie altyd so duidelik na vore gekom het nie, wil ek die feit van sy bydrae konstateer deur hierdie studie te wy aan ' $n$ kombinasie van die twee genoemde belangstellings: vroue in die sending en vroue in die kerklike amp.

Om volledig aandag aan beide komponente te gee sou vir een studie te uitgebrei word. Ons gaan dus hier nie volledig in op die rol wat die vrou in die sendinggeskiedenis gespeel het nie. Tog is dit nodig om as vertrekpunt na die vrou in die sendingopset te verwys (1:13), om dan daarna verder te handel oor die vrou in die kerklike amp.

\section{Vroue en sending}

Van die vroegste Christelike era af, is vroue in verband met die verlossingsboodskap besonderlik begenadig. Om net enkele voorbeelde te noem: Die vrou Maria word die inbrengster van die Verlosser in die wêreld (Luk 1:30). Paulus sê daarby: "so is ook die man (alle mans buiten Adam, maar wel die tweede Adam) deur middel van die vrou" (I Kor 11:12). Vrouens was die eerste draers van die opstandingstyding (Matt 28). 'n Vrou was die eerste Christen in die Westerse wêreld (Hand 16:14).

Daar is waarskynlik verskeie naspeurbare redes waarom bantoevrouens ' $n$ groot rol in die Christendom onder hulle, speel.

Die bantoemans (verder genoem mans) wat in nywerhede werk wie se gesinne miskien in die tuisland is, is verder as die vrouens gesekulariseer. Die verwerpingsimptome van alle geloofsake is by die vrouens dus minder sterk.

Die langdurige arbeid van die mans, laat min rustige tyd oor in hulle tuistes om oor kerksake en geloofsake te handel. Met die vrouens is dit enigsins anders gestel. Indien hulle tuis bly, het hulle 
rustiger bedenkingstyd. Indien vrouens huisbediendes is, kom hulle op 'n sagter wyse in kontak met die Westerse Christelike beskawing. Daardeur word hulle vatbaarder as die mans omdat laasgenoemde dikwels slegs op die harde terrein die Christen waarneem.

Omdat die mans elke weekdag in stedelike gebiede in sy werk betrek is, selfs van baie vroeg tot baie laat as ons sy busvervoer in gedagte hou, gebruik hy Sondae vir sportaangeleenthede.

Die gedagte leef ook dat kerksake nie mans-sake is nie, maar vrouens-sake. Die vrou abba die baba, voed hulle nog aan lyf. Dis 'n rare verskynsel om ' $n$ bantoeman te sien kinders roed en versorg. Kindervoeding is nog 'n baie belangrike lewenstaak (ook vanweë die groot getalle kinders) juis van die vrou - die bantoemoeder of grootmoeder. Kersteningswerk word geassosieer met die opvoedingstaak, en dit word gesien as ' $n$ vrouenstaak.

Ondersoekers wys verder daarop dat vrouens ook getrouer vereerders van die voorvaders is, as mans (2:105). Hierin word gemeen om 'n verder oorsaak te vind vir die vrou se groter belangstelling in die Christelike geloof. Die rede lê in die vroulike soek na sekuriteit. Veral die bantoevrou wat met 'n karige salaris of toelaag, alleen 'n groot getal kinders moet versorg, voel benoud. Hulle besef hulle afhanklikheid sterker en soek daarom na vastigheid, hulp, koers.

By baie swart kerke, selfs ons Afrikaanse kersteningskerke (2:106), word die "gees gekry". Omdat hierdie ervaring 'n psigologiese bevrediging is vir bantoevrouens wat bekneld oor die huishouding en lewensituasie is, word hulle daarheen getrek. Ons kan egter vermeld dat uitsonderlikhede soos hierdie en ander derglike verskynsels redelik vreemd in die Hervormde Kerk van Suidelike Afrika is. Sekere danse wat tradisioneel by bantoevrouens is en ook by stedelike gemeenskappe nog voorkom, selfs onder kerkgenootskappe, en waarin die vrouens ook ontspanning vind, is grootliks onbekend by ons kersteningskerk.

'n Mens vra jou ook die vraag af hoe ver die tradisionele poligamie 'n neerslag in die kerk van die bantoe het. In die tuislande is die poligamie meer direk en onder die ontwortelde stedeling miskien nog vanweë erflike neerslae, 'n oorsaak van 'n sekere mentaliteit. Die poligamiese huwelik bestaan uit één man met baie vrouens. In watter mate werk dié lewenspatroon deur sodat in die huishouding van die kerk ook meer vrouens tereg kom as mans?

\section{Onderwaardering van die vrou}

Deur die eeue het ons oor die algemeen 'n onderwaardering van die vrou. Milton het gesê 'n vrou is 'n skone gebrek. Vondel se wysheid is dat "één vrouw is duisend mannen te ergh". Aristoteles meen dat 'n vrou 'n vrou is vanweë gebrek aan kwaliteit. Tertullianus sê dat 'n 
vrou ' $n$ tempel is wat oor 'n riool gebou is. Tomas van Acquino beweer dat 'n vrou 'n toevallige bederf van die natuur is. Die Chinese het tot onlangs dogtertjies se voetjies afgebind sodat hulle nie later sou wegloop of rondloop - onder die gesag van die man uit nie (3:17).

Hierdie enkele voorbeelde sou baie uitgebrei kan word omdat dit vir baie beskawings in baie eeue feitlik vanselfsprekend was dat die vrou die wesenlike mindere van die man is. Algemeen bekend is dan ook die Rabbynse standpunt wat skakel met die historiese OuTestamentiese beskouing van die vrou, dat 'n "mens" nie met 'n vrou in die openbaar praat nie (Joh 4:27), selfs nie met jou eie nie. In die straat loop sy gesluier 'n entjie agter jou!

Is dit nie ook hierdie onderwaardering wat vroue hekse gemaak het nie? Sy is as helledeur gesien.

\section{Orwaardering van die vrou}

Omdat die oorwaardering van die vrou histories 'n rariteit is, maar wel 'n verskynsel is, moet daarna verwys word.

Veral in ons dag is bewegings soos die sogenaamde Womens liberation soms blindelings besig, nie om net die vrou hoër te waardeer nie maar ook wan te waardeer. Geen Christen sal seker beswaar hê as die vrou hoër gewaardeer word as die historiese waardering nie, maar die vrou word soms linksweg gewaardeer. Daarmee word sy weggeneem van die man se regterhand as hulp wat by hom pas (Gen 2:18).

Die oorwaardering van die vrou wat ook 'n motief tot emansipasie van die vrou is, is egter nie net 'n moderne verskynsel nie. In 1509 al het Heinrich Cornelius Agrippa von Nettesheim 'n studie geskryf waarin hy betoog dat die vrou die man se meerdere is (40:40-43).

Ons noem enkele van die argumente wat gebruik word om te bewys dat die vrou die man se meerdere sou wees. Die eerste is die komposisie van Genesis 2 se skeppingsverhaal. Hiervolgens sou die vrou die meerdere van die man wees omdat sy ná die man geskape is. Die komposisie van Genesis 2 sou dan 'n opgaande lyn vertoon van die een soort na die ander. Verder word betoog dat die moeder meer van haarself aan ' $n$ kind gee as die vader. 'n Vrou, soos Maria, kan selfs geboorte aan 'n kind gee sonder 'n man. Maar andersom gebeur dit nooit. Die laagste skeppingstrata is stil. Hoe hoër die skepping opgaan hoe luidrugtiger word dit. Die planteryk is geluidvoller as die klippe; die diere se geluide sinvoller as die planteryk s'n. Die mens se spraak is ver bo die geluide van alle laere skeppingsvorme. Maar die vrou se gesprekke sou dan nog veel meer en sinvoller wees as die man s'n!

Dat die priesters almal mans was in die Ou-Testamentiese tyd 
word deur Von Nettesheim verklaar as ' $n$ aanduiding van manneminderwaardigheid! Die sonde moet uitgeboet word in die geslag wat die meeste gesondig het. Daarom moes die manne-priesters elke dag herinner word deur hulle offers aan hulle sonde. Daarom het Jesus ook 'n man geword om aldus in die nederigste staat (Filip 2:8) van menswees te kom. Dit sou dan ook die man (Adam) wees wat die vrou (Eva) nie goed genoeg onderrig het oor wat God aan die man gesê het in verband met die eetgewoontes in die Paradys nie. Sy was dus deur die man swak toegerus en daarby het hy ook nie - terwyl hy van beter weet - sterk genoeg weerstand gebied teen haar verleiding nie.

Von Nettesheim beklink sy argument deur daarop te wys dat die edelste van mense, Jesus, uit 'n vrou gebore is, terwyl die laagste daad aan Jesus, dié van verraad, deur ' $n$ man gepleeg is. Die vrou word dus as hemeldeur gesien.

\section{Die skepping en die vrou}

Gaan ' $n$ mens die skeppingsverhale na in Genesis 1 en 2, dan blyk dit dat die vrou as mens wesensgelyk aan die man geskape is, maar dat die mens as vrou posisioneel tweede aan die man is (4: ). Sy is nie sekondêr aan die man geskape in die sin van tweederangs nie. Sy is primêr - omdat God self die goedheid daarvan ingesien het, dat dit noodsaaklik is dat sy geskape moes word (Gen 2:18).

Uit die letterkundige komposisie van die skeppingsverhale van Genesis self, blyk nie alleen dat die vrou wesensgelyk aan die man geskape is nie, maar ook dat sy nie as sy meerdere geskape is nie. Dit is wel waar dat in die skepping ' $n$ opgaande lyn te bespeur is: die een soort wat ná die ander soort geskape is, is hoër en ook goed. Maar hierdie opgaande lyn is volgens die skeppingsverhale self, nie van toepassing op die verhouding man:vrou nie. Sy is wel ná die man geskape. Sy is geskape omdat van die man nie gesê is dat sy skepping goed is nie, maar omdat van hom gesê is: Dit is nie goed dat die mens alleen is nie (Gen 2:18). Die vrou se skepping is bykomstig maar primêr aan die man s'n. Hulle twee sáám word eers genoem met mutatis mutandis die ekwivalente van "toe sien God dat dit goed was" naamlik: "En God het die mens geskape na sy beeld".

Beide is saam na die beeld van God geskape; dit is een "soort" skepping, nie twee soorte met die opgaande lyn nie. Sy is uit die man geneem - mannin (Gen 2:23); wesensgelyk. Die een soort in die res van die skepping is nie by name as hulp vir die laere soort geskape nie; terwyl by die vrou sy as hulp geskape is - nie as meerdere nie. Ook Paulus het Genesis so verstaan dat Eva se skepping ná 
Adam, nie dui op meerderwaardigheid van die een geslag bo die ander nie, maar dui op posisionele onderdanigheid van die vrou aan haar man (I Tim 2:12, 13).

\section{Die sondeval en die vrou}

Die skeppingsgegewe posisionele verhouding tussen man en vrou van hoof: hulp, het vanweë die sondeval verval in 'n wesenlike disharmonie.

Al die disharmonie in menseverhoudings tussen die geslagte en menslike gemeenskappe en volkere, kan prinsipieel teruggevoer word na die sondeval. Wat in die skepping as posisionele verskil tussen man en vrou bedoel was, het beskoulik verword tot wesenlike verskil sodat soms ' $n$ vroue-georiënteerde kultuur ontstaan het (dink byvoorbeeld aan die matriargale kanaänitiese natuurreligie) maar meerendeel 'n manne-georiënteerde kultuur - die androgeniese kulture.

God se straf wat Hy uitspreek oor die mens se sonde, bevat genade. Indien God nie gereël het dat die man oor die vrou sou heers (vanweë haar prioriteitsaandeel in die sondeval) nie, was daar geen ordereël in die ontstane disharmonie nie (Gen 3:16; I Tim 2:14; II Kor 11:3). Die ontstaan van androgeniese kulture is deels dus ook te danke aan hierdie ordereël van God.

Dat die een volk, Israel, later uitverkies word deur God, word deur Israel self vanweë die sonde so opgeneem asof hulle wesenlik beter is as ander volke (Jer 7:4). So het ook die Grieke gedink; 'n gedagte waarteen Paulus waarsku (Hand 17:26). Die Jode het hierdie veronderstelde wesenlike meerderwaardigheid van hulle bo ander, so ver gevoer dat waar 'n Israeliet selfs die doodstraf kon kry vir owerspel (Deut 22:22), die Talmud 'n Israeliet vry spreek as die ontug met ' $n$ nie-Jood was (5:739)! (Is hierdie situasie nie die teenoorgestelde in sommige fasette van ons huidige wetgewing in verband met "ontug" en owerspel nie?)

Dat mense moet saamwerk en die aarde moet onderwerp (Gen 1:28) en Eden moet bewerk en bewaak word (Gen 2:15), het na die sondeval uitgeloop op doodslag en verslawing. In plaas van saamwerk het die een die ander vermoor of tot slaaf gemaak.

Vanweë die sondeval het daar dus onder andere androgeniese kulture ontstaan. En hierdie manne-georiënteerdheid is tradisioneel nog steeds waarneembaar in die Nuwe Testament, byvoorbeeld I Korintiërs $1: 10 ; 3: 1 ; 4: 6 ; 10: 1 ; 11: 2$ (vgl v 5!); 12:1; 14:26; 15:1; en andere waar slegs die broeders aangespreek word maar die hele gemeente - die susters ook - bedoel word. 
Die historiese androgeniese en ander verworde kulture, staan in die lig van die herskepping as sondig gebrandmerk. In Christus ontstaan by wyse van herskepping Christelike kulture. In Christus is daar nie plek vir die beskouing van wesenlike verskille tussen volk en volk (Israel:Griek), klas en klas (slaaf of vryman), en geslag en geslag (man en vrou) nie (Gal 3:28; Kol 3:11; Ef 2:14). Die posisionele en natuurlike verskille as geen wesensverskille nie, word in Christus nie opgehef nie. Christus hef wat vanweë die sonde gekom het, op. Hy hef die skepping nie op nie.

In Christus behoort die vrou nie meer as ' $n$ stuk eiendom aan die man nie - asof sy wesenlik sy mindere is nie. Maar in Christus behoort die man se liggaam aan die vrou en die vrou s'n aan die man (I Kor 7:4), maar beide behoort aan Christus (Rom 7:4).

Indien daar geen menslik-wesenlike verskil tussen man en vrou is nie, waarom het God nie die androgeniese kultuurvorme soos in die Bybel weerspieël, meteens omvergewerp nie?

God se besondere handele in die geskiedenis is volgens die Bybel gewoonlik nie rewolusionêr nie: "Nie deur krag of deur geweld nie, maar deur my Gees, sê die Here van die leërskare" (Sag 4:6). So is die poligamie waarvan ons in die Ou Testament ook lees, byvoorbeeld by Dawid, Salomo, die aartsvaders en ander, sondige gestaltes van die huwelik, maar God het poligamie nie toe rewolusionêr omver gewerp nie. Vandag nog kry ons op die sendingveld met poligamie te doen, maar die suurdeeg van die evangelie suiwer dit geleidelik uit. In die Nuwe Testament lees ons dikwels nog steeds van slawe. Paulus stuur die slaaf van Filémon, Onésimus, aan hom terug (Filémon $1: 11$ ). Nou is Onésimus ' $n$ Christen en hy sal baie nuttig vir sy heer wees. Tot voor die aanvang van die Groot Trek in die vorige eeu, het ons eie voorouers nog slawe gehad. Die Here het slawerny nie rewolusionêr omver gewerp nie, maar geleidelik evangelies geabsorbeer. So gebeur dit ook dat verhoudings tussen nasies en rasse nooit per rewolusie waarlik in die reine kan kom nie, maar wel deur die inwerking van die evangelie. Ook die androgeniese of watter sondige kultuurgestaltes ookal, word evangelies dikwels geleidelik maar radikaal omskep.

\section{Die vrou en die ampte}

Dat die ampsdraers ook in die Nuwe Testament nog veelal mans was, is heeltemal te verstaan teen die manne-georiënteerde kultuur van daardie tyd. Teen hierdie agtergrond is die sanhedrin of Joodse Raad slegs mans. Die sanhedrin se schaliach is ook' $n$ man. Hy word 
deur die sanhedrin as gevolmagtigde gestuur na wie of waar ookal om die sanhedrin te verteenwoordig (6:257). Volgens Handelinge 8:3 en Galasiërs 1:13 kon Paulus dalk so 'n schaliach gewees het. Inhoudelik is die Ou-Testamentiese voorloper van die apostel die profeet (7:21), maar tegnies is die apostelamp se voorloper stellig die schaliach. Paulus het dan as Christen-apostel tegnies voortgesit wat hy eers as Joodse schaliach was. Waar die schaliach waarskynlik 'n ouderling was, is die apostelamp ' $n$ variant van die ouderlingamp destyds 'n manneamp (6:257).

Die chazzan weer was uitvoerende beampte van die sinagoge, 'n priester, 'n man. Hierdie helper, huperetes, het in die Christelike kerk evangelis, diaken en dalk nog meer, geword (6:257). Soos die rabbie deur hierdie hulp bygestaan is in alles (Neh 8:18), so was Timoteus en Erastus Paulus se helpers (Hand 19:22).

Dit lyk asof die helper, die diaken en die evangelis in die Nuwe Testament dieselfde amp beklee. Of was dit destyds maar nog net onuitgesorteerd en vloeiend (8:67)? In Handelinge 21:8; 6:58; 8:5, 6, 35-40 lees ons van twee diakens Filippus en Stéfanus wat die Woord verkondig en selfs doop. In Efesiërs 4:11 word diakens nie genoem nie, wel evangeliste, terwyl die diakensamp die mees genoemde elders is, en die evangeliste net in Efesiërs 4:11 en Handelinge 21:8 en II Timoteus 4:5. Is dit ' $n$ aanduiding in hierdie belangrike opsommende Efesiërs 4:11 dat die belangrike diakonaat ingesluit is as die evangeliste genoem word? Die diaken-evangelis-helper het die apostels bygestaan met betrekking tot 'n besondere groep - die Griekssprekende Jode (Hand 6). Hulle dien die apostel in die algemeen (Hand 19:2) en in die besonder die apostel self (Kol 4:7, 12; Ef 6:21; Filip 4:18). Indien die helper, evangelis, diaken en selfs leraar sy oorsprong in die sinagogale chazzan het, is dit in elk geval weer eens te verstaan dat dit hoofsaaklik 'n manne-amp in praktyk was.

\section{Simptome van verandering}

Die Gees van die Here het in die Ou-Testamentiese tyd voor die koms van Christus, maar veral na die koms, baie simptome laat bekend word van die omskepping van die androgeniese samelewing in 'n Christelike.

As voorbeelde van hierdie simptome verwys ons na Mirjam, 'n profetes en volksleier (Eks 15:20; Miga 6:4). Sy het net soos Debóra (Rig 4:5) 'n profetiese en koninklike amp beklee. Net soos Debóra, die vrou van Lappidot (Rig 4:4), was ook Hulda getroud (II Kon 22:14 v). Hulda het geprofeteer tot die priester, die koning en die volk. En haar spreke was in ooreenstemming met die wetboek wat weer gevind is. In hierdie profetiese amp, waarin die predikant vandag 
staan, was daar ook verkeerde woorde sowel van profetesse as van profete. Dink aan Noedja (Neh 6:14) en Isébel (Open 2:20). Nie net in die profetiese en koninklike ampte nie maar ook as hulp by die priesterlike amp, vind ons reeds in die Ou Testament vrouens (Eks 38:8; I Sam 2:22).

In die Nuwe Testament kry ons Anna, die profetes (Luk 2:36). Vroue was bevoorreg om die eerste draers van die opstandingsboodskap, die evangelie, te wees (Matt 28). Die Heilige Gees is op almal mans en vroue - uitgestort om hulle toe te rus om getuies van Christus te wees (Hand 1:8, 14; 2:1-13). Filippus se vier ongetroude dogters was met hulle profetiese gawes sekerlik diensbaar in die kerk (Hand 21:9). Prissilla het saam met haar man Akwila vir Apollos, 'n man, die weg van God noukeuriger uitgelê (Hand 18:26). Sy word Paulus se sunergos, medewerker, genoem (Rom 16:3). Só is ook Timoteus (Rom 16:21) en Epafroditus (Filip 2:25) genoem, wat Paulus se helpers was of diakens of evangeliste. In Romeine 16:1 kry ons Fébé wat behalwe dat sy 'n gelowige (suster) was, ook'n diakones van die gemeente Kenchréë was. Maria het baie gearbei (kopia-o = werk dat jy moeg word, labor) in kerklike verband (Rom 16:6). Ook triféna en Trifósa het harde arbeid (kopia-o) in die Here verrig (Rom 16:12). Euódia en Sintiché het saam met Paulus "atletiek gedoen", gekompeteer in die evangelie (Filip 4:3). In I Timoteus 5:3-16 en Titus 2:3-5 lees ons van die weduwees wat die kerklike amp kon beklee en so ook van vroue waarskynlik in die amp in I Timoteus 3:11 (9:29). Bekend is ook Calvyn se onderskeiding op grond van Romeine 12:8 van twee diakensgroepe: ontvangers, wat administratiefregerend mans moes wees, en versorgers wat vroue kon wees (Institusie IV, III, 9).

Simptome van die geleidelike omskepping van die androgeniese kultuur ten opsigte van kerklike sake, sien ons ook in die sakramentsgebruike. In die Ou-Testamentiese tyd is net seuntjies besny (Gen 17:10). Die doop kom in die plek van die besnydenes (Kol 2:11, 12). Tog doop ons sedert die Nuwe-Testamentiese tyd ook vroue en dogtertjies. Die Here stel die nagmaal in met slegs mans teenwoordig. Tog gebruik vroue vandag sonder opspraak nagmaal. Nie lank gelede nie het mans en vroue in hierdie volgorde apart nagmaal gebruik. Vroeër het mans en vrouens selfs apart gesit in die kerk. Dis ook maar onlangs dat vroue in ons Kerk stemreg gekry het. En sedert 1970 kan vroue as diakens in ons Kerk verkies word.

Niemand het vandag beswaar dat vrouens in die onderwys seuns van 18 jaar onderrig nie. Vroeër was 'n man van 18 jaar dalk al wewenaar soos byvoorbeeld die geval met Paul Kruger. Weekliks onderrig of katkiseer vroue seuns van enige ouderdom in die kategese.

Van die Protestanse kerke in die wêreld het $72 \%$ al die vrou in een of ander amp toegelaat. In 1958 het die Nederlandse Hervormde Kerk 
die vrou tot die amp toegelaat; en in 1968 het die Gereformeerde Kerk in Nederland dit gedoen (6:243).

\section{Die vroue van ampsdraers}

Die Nederduitsch Hervormde Sustersvereniging doen reusewerk in ons Kerk. Op hierdie wyse staan die vrouens die mans en/of ampsdraers by. Die NHSV is 'n hulporgaan in die Kerk - volgens ons Kerkwet ook.

Maar miskien sou die organisasie of arbeidsomvang van die NHSV daar anders uitgesien het - of miskien sou die NHSV dalk nie eers bestaan het nie - as die vrouens van ampsdraers almal hul verantwoordelike deel gedoen het. Die vrou is die hulp vir die man - in alle opsigte ook wat die kerklike ampswerk betref. As die ampsdraer dus 'n getroude man is, het hy vir hierdie werk' $n$ hulp wat by hom moet pas.

Daarom redeneer Paulus volgens I Korintiërs 9:5 ook so dat hy as apostel die reg het om 'n suster as vrou met hom rond te neem net soos die ander apostels en die broers van die Here en Cefas. Paulus sê nie hier dat hy dit doen nie. Hy verdedig sy apostoliese regte. Hy het reg om van die evangelie te lewe, dit wil sê deur hulle wat onder sy bediening is, getrakteer te word. Maar hy maak van daardie reg nie altyd gebruik nie (I Kor 9:18). So het hy die reg om 'n vrou wat homself behulpsaam kan wees in sy ampswerk, as sy eie vrou saam te neem. En dan moet sy ook getrakteer word deur die gemeente. Hy maak ewenwel van hierdie reg ook nie gebruik nie. (Volgens hierdie redenasie van Paulus sou ons ook kon sê dat 'n predikant wie se vrou nie ' $n$ buite-amptelike salaris verdien nie, maar haar man voltyds in sy amp bystaan, geregtig daarop is om deur die gemeente getrakteer te word. Paulus stel 'n voorwaarde waaraan so 'n vrou vir hom sou moes voldoen: sy sou 'n gelowige (suster) moes wees. Dui dit daarop dat 'n gelowige nie met 'n ongelowige mag trou nie? Vergelyk ook II Korintiërs 6:14).

Nou dat die vrou ook in die kerklike amp begin betrek word as ampsdraer, is dit jammer dat sy 'n groot sprong moet maak. Ons gaan haal haar te ver om haar dan meteens in die amp te plaas. Sy moes eerstens by die amp geplaas gewees het. Miskien het ons op androgeniese kultuurgrondslag haar ver gehou en dat die Gees van die Here deur sy Woord en kerk haar self nou sprongsgewyse nie net naby nie maar in die amp plaas.

Dan is dit hoog tyd dat ons die vroue van predikante in predikantevergaderings, die vroue van ouderlinge in ouderlingsvergaderings en die vroue van diakens in diakensvergaderings verwelkom. Dis eweneens dringend dat elke getroude vrou haar paslike plek in haar man se ampsbediening inneem. 


\section{Die probleem tekste}

Ons bepaal ons by drie.

(a) I Korintiërs 11:5 word deur sommige Skrifkenners aangepas by I Korintiërs 14:34, 35 deur eersgenoemde, waar die vrou mag profeteer, te betrek op privaatbyeenkomste, en laasgenoemde, waar sy nie mag spreek nie (lalein), te betrek op gemeentelike byeenkomste (10:370). "Daar is ook getrag om die kontroverse op te hef deur die charismatiese spreke van I Korintiërs 11:5 te stel teenoor die niecharismatiese van I Korintiërs 14:32-36. Dan word 'lalein' vergelyk met 'didaskein' ... Maar onderrig gee in die gemeente is ook 'n genadegawe. Van 'n nie-charismatiese spreke in die gemeente is eenvoudig geen sprake nie" (20:62). Die gedagte is dat die vrou eenvoudig deur die Heilige Gees gedwing word om te spreek. As dit die geval was, is die vrou in elk geval deur die Heilige Gees "waardig" geag om te profeteer. Maar in I Korintiërs 11:5 waar sprake is dat sy spreek, is sprake van profeteer en in I Korintiërs 14 waar sy "charismaties" sou kon spreek (lalein) word sy juis verbied!

Ondersoekers wy nie veel aandag daaraan om die skynbare teenspraak tussen I Korintiërs 11:5 en I Timoteus 2:11-15 só te beskou soos dié tussen I Korintiërs 11:5 en I Korintiërs 14:34, 35 nie, omdat die moontlikheid bestaan dat Paulus nie die skrywer van die pastorale briewe is nie (13:4-8).

Die gegewens rondom I Korintiërs 11:5, dat sy profeteer ('n gemeentelike saak - I Korintiërs 14:4) en dat sy haar hoof moet bedek, wys onmiskenbaar nie op 'n huis- of privaatbyeenkoms nie, maar 'n gemeentelike (6:259).

As riglyn vir vroue-predikante kan ons uit I Korintiërs 11:5 sê sy moet só predikant wees dat haar vroulike posisie teenoor haar hoof, haar man (8:77), nie in die gedrang kom nie.

Die skeer en ontbloting van die vroue-hoof was destyds teken dat die vrou haar man nie eer nie. Dit het ' $n$ besondere betekenis in die hawestad Korinte gehad.

(b) I Korintiërs 14:34, 35 se swyggebod word deur sommige verklaarders (Weiss en Conzelmann) weg-geïnterpoleer as 'n latere, onaanvaarbare byvoeging. Andere aanvaar dit as gewoonweg ' $n$ swyggebod vir vroue in die gemeente (Grosheide) en korreleer dit met I Korintiërs 11:5 soos voorheen aangedui. Köhler, Wendland, Pelser, en andere wys daarop dat in hierdie gedeelte dit om iets anders as preek gaan (6:260).

Dit gaan hier om die orde in die byeenkoms. 'n Deurmekaar gepratery wat 'n babelse wanorde afgee, soos vrouens destyds soms opgetree het, word by vrouens $(v 34,35)$ maar ook by enigeen $(v 28$, 30) nie toegelaat nie.

In hierdie geval het vrouens, bevry van sonde in Christus hulleself 
as sodanig geëmansipeerd van hulle gelowige mans geag en in die byeenkoms allerlei vrae gevra. Hulle gelowige mans is tuis die aangewese gespreksgenoot.

(c) I Timoteus 2:11-15. Sonder om al die standpunte hier sistematies weer te gee $(6: 261-265 ; 7: 28-32 ; 13: 17-18 ; 14: 40-41 ; 15: 1-11)$, beweeg baie verantwoordelike verklarings in die rigting "dat die vrou nie toegelaat word om haar man te onderrig of oor hom te heers nie" (7:30). Hierdie standpunt meen ek nader te kwalifiseer met as hipotese dat dit hier gaan om gelowige getroude vrouens wat hulle ongelowige mans (ook in die byeenkomste) alwys baasspelerig wil onderrig. Die volgende is moontlike aanduidings vir hierdie hipotese:

(i) Volgens $v 11$ het sy nog iets te leer - sy is nie alwys nie.

(ii) In die Nuwe Testament word die onderdanigheid van die vrou aan haar eie man beklemtoon (I Petr 3:1; Ef 5:22). Juis in Efese moet Timoteus op Paulus wag (I Tim 1:3; 3:14).

(iii) Dit gaan in hierdie perikoop om die gesindhede in die byeenkoms. Manlike voorgangers moet nie toornig wees en twis nie (v 8), vroulike voorgangers (en andere) se kleding moenie opvallend of aandag aftrekkend wees nie $(\mathrm{v} 9,10)$. Gelowige vroue in die byeenkoms moenie hulle ongelowige mans oormeester nie ( $\mathrm{v} 12$ ).

(iv) Vrouens kom soms gouer tot die Christelike geloof as hulle mans. Dink aan die geval onder swartes soos aan die begin genoem. In I Korintiërs 7:10-14 word die moontlikheid gekonstateer dat huweliksgenote nie gelyktydig gelowig word nie. Dit skemer wel deur dat in die praktyk dit soms eerder die vrou is wat eerste gelowig word. In I Petrus 3:1 kom dieselfde tema as in ons perikoop na vore: "Net so moet julle, vroue, aan jul eie mans onderdanig wees (al het julle tot die Christelike vryheid gekom), sodat, as sommige aan die woord ongehoorsaam is, hulle ook deur die wandel van die vroue sonder woorde gewin kan word."

(v) In I Korintiërs 14:34 word lalein gebruik omdat dit daar nie om ongelowige mans in daardie situasie gegaan het nie ( $v 35)$, maar in ons perikoop se situasie word didaskein gebruik, wat hier dui op geloofsonderrig aan haar ongelowige man.

(vi) Dat ons onderhawige situasie 'n vrygemaakte vrou oftewel Christin kan aandui wat 'n verkeerde gesindheid teenoor haar man openbaar, vind miskien ook in I Korintiërs 11:5 grond. Dáár is aanduiding dat die vrou mag spreek maar sy moet let op die wyse waarop sy dit doen. Sy moet dit vroulik doen.

(vii) Die Christen-vrou kon 'n verkeerde opvatting oor haar nuutverkreë Christelike vryheid hê. Die Joodse sinagoge het die vrou slegs as toehoorder toegelaat. Maar in die Korintiese gemeente het die Christin kon profeteer. Hierdie Christelike (teenoor Joodse) moontlikheid het wel soms probleme gegee in 'n wanontwikkelde 
emansipasie wat sektaries uitgebuit is volgens II Timoteus 3:6 (13:17).

Die Griekse Christene veral het in sommige gevalle (12:136) byvoorbeeld gedink dat die Christelike vryheid (Joh 8:36) 'n arbeidsemansipasie inhou (3:87). Daarom word hulle tot arbeid vermaan (I Tess 4:11; II Tess 3:10). So kon die vroue ook dink as hulle verlos is, is hulle nie meer posisioneel aan hulle mans onderdanig nie. Miskien skemer daar ook gnostiese huweliksonwil (21:74-84) deur in ons perikoop soos in I Timoteus 4:3 en I Timoteus 5:13-15 (14:40). Dan kan dit wees dat die vrou wat miskien meer aangetrokke was en getref is deur die gnostisisme, in daardie omstandighede verbied was om te leer, omdat haar leer aktiwiteit 'n groot risiko in daardie omstandighede was (20:67). Daarom dat in Titus 2:3 staan dat die ou vrouens "kalodidaskalous" moet wees - leraresse van wat goed is (Titus 2:3). Dit sou ook beter pas by 'n post-Pauliniese datering van die Timoteusbriewe in hulle finale vorm (22:25) - omdat die gnostisisme later sterker was. Sou dit kon wees dat die "ongelowige" man dan dalk 'n gewone gelowige was, en sy vrou 'n gnostiese gelowige?

(viii) Die vrou se verkeerde opvatting van haar nuut verkreë vryheid in Christus, bring haar tot onderrig (didaskein) waarin sy van haar man gehoorsaamheid eis (16:82). Ja, dit bring haar tot dominerende dwang oor haar man - authentein andros. Die woord vir dominering hier (authentein) is ' $n$ hapax in die Nuwe Testament (17:120). Dit onderstreep dus ook die uitsonderlike situasie waarmee ons hier te doen het.

(ix) In vers 12 sê die skrywer dat hý dit nie toelaat nie. Met ander woorde hierdie formulering wys op 'n persoonlike standpunt, vanweë lokale omstandighede soos in I Korintiërs 7:6. In I Korintiërs 14:34 word gesê as 'n algemene reël dat dit die vroue nie toegelaat is om wanordelik te wees nie - waar dit die mans sóú geld, natuurlik hulle ook.

(x) In die motivering waarom die vrou nog steeds na haar verlossing-vryheid posisioneel aan haar man onderdanig is, word eerstens na die skepping verwys ( $v 13$ ), dan na die sondeval (v 14) en laastens na die herskepping (v 15). Omdat die man (Adam) voor sy vrou (Eva) geskape is, het hy die "eersgeboortereg" (14:41). Dat die oudste rangordelik prioriteit daardie tyd geniet het, bemerk ons ook in Kolossense 1:15; Efesiërs 1:4; Johannes 1:1; en in die Joodse skrywers wat graag sê: die muggie, die vlieg, die wurm is voor jou geskape, waarom is jy dan hoogmoedig mens? $(18: 44,45)$. Wat die sondeval betref, word die vrygemaakte vrou gewaarsku dat die volmaakte vrou primêr verlei is. Vergelyk ook II Korintiërs 11:3 wat die volgende stelling weerlê: "Vers 14 (I Tim 2) is die enigste plek in die Nuwe Testament (of die hele Bybel) waar ons die gedagte aantref dat Adam nie verlei (is) nie"' (7:31). Ook die bevryde vrou moet dus nie voorba- 
rig wees nie. Wat die se vrou herskepping of verlossing betref, is daar egter hoop. Terwyl sy haar natuurlike rol as moeder vervul en haar as bevryde in Christus nie van haar man bevry nie, maar voortgaan om vir hom sy vrou te wees en sy kinders te baar, is haar verlossing nog 'n werklikheid. Haar verlossing is nie instrumenteel deur haar moederlikheid nie, maar haar moederlikheid (en vroulikheid) moet begeleidend wees aan haar verlossing. Hulle, die vrouens (19:64), se verlossing is (soos vir almal) geleë in hulle volharding in geloof en liefde en heiligmaking (maar vir die vrou) met ingetoënheid (= met alle ordentlikheid). Laasgenoemde beaam finaal die tema van die perikoop.

\section{Die praktyk}

Alles in oënskou genome, sou ons konkludeer dat die vrou nie wesenlik uit die kerklike ampte uitgesluit is nie. Haar beterweterigheid, oorheersing of regeeraktiwiteit oor haar man in die destydse situasie, sou die vrou in die algemeen egter nie te alle tye verhinder om byvoorbeeld ook 'n ouderling te word nie (6:263). Maar dit sou nie reg wees (areston, Hand 6:2) indien sy haar vroulikheid - met alles wat daarmee saamgaan - oorboord gooi nie. In gevalle en omstandighede waar dié risiko nie aktueel is nie, kan sy geroep word deur die gemeente en daarom deur God self, om ook besondere ampsdraer van die evangelie te wees.

\section{Verwysings}

1. Dr H G van der Westhuizen, Vroue in die Kerk, Die Hervormer, November 1976.

2. Dr A G Schutte, Swart Doppers, NG Kerkboekhandel, 1974.

3. Dr H G van der Westhuizen, Vertrou op God, HAUM, 1977.

4. Dr H G van der Westhuizen, Egbreuk, Hervormde Teologiese Studies, Jaargang, Ter perse.

5. Hauck, Theologisches Wörterbuck zum Neuen Testament, Band IV.

6. Prof dr D J G van der Merwe, Die vrou in die kerklike amp, ja of nee? Nederduits Gereformeerde Teologiese Tydskrif, Junie 1977.

7. Prof dr P S Dreyer, Vroue as Predikante, HAUM, 1977.

8. Ds E Engelbrecht, Diakonein, Hervormde Teologiese Studies, Junie 1971.

9. Prof dr B J Engelbrecht, Die Amp van die Diaken, NHW-Pers, 1957.

10. F W Grossheide, De eerste brief aan de Kerk te Korinthe, Kampen, 1957.

11. Gottfried, Holtz, Die Pastoralbriefe, 1964.

12. Dr J A C van Leeuwen, Colossensen, Thessalonicensen, Korte Verklaring van de Heilige Schrift, J H Kok NV Kampen 1966.

13. Joachim Jeremias, Die Briefe an Timotheus u. Titus - Das Neue Testament Deutsch 9, Gottingen, 1954.

14. Dr T H C de Kruift, De Pastorale Brieven, J J Romen \& Zonen, MCMLXVI.

15. Ds J J Steenekamp, Ongepubliseerde manuskrip.

16. Dr Herman Ridderbos, Pastorale Brieven, 1967.

17. Amdt-Gingrich, A Greek-English Lexicon of the New Testament and Other Early Christian Literature, 1952.

18. E L Smelik, De Wegen Der Kerk, deel X, Callenbach 1947. 
19. Dr C Bouma, Korte Verklaring, 1,11 Timotheus en Titus, Filemon, Kampen Kampen 1953.

20. J Annandale, Die Vrou in die amp, BD-skripsie, Universiteit van Pretoria, 1962, NG kerkargief, Pretoria.

21. F F Bruce, First-century faith, Inter-Varsity Press, England, 1977.

22. G M M Pelser, Women and Ecclesiastical Ministries in Paul, ongepubliseerd. 